\title{
A. en el País de las maravillas (normalizadas)
}

Notas al margen del primer Neufert

\section{A. in Wonderland (normalized)}

\section{Marginal notes in the first Neufert}

\section{Fernando Magarzo, Ana}

Universidad Politécnica de Madrid, Departamento de Proyectos, Escuela Técnica Superior de Arquitectura (ETSAM), Madrid, España, anafernandomagarzo@yahoo.es

\begin{abstract}
Resumen
Imaginar el reciente hallazgo de un ejemplar de la primera edición del Arte de Proyectar en Arquitectura, repleto de asombrosas anotaciones al margen, y no tan al margen, arrojaría un nuevo interés, y completamente inesperado, sobre el que ha sido durante mucho tiempo el manual de la normalización y el estandarte de la funcionalidad por excelencia.

El gran vademécum habría sido encontrado en la última casa de Ernst Neufert, en Bugneaux-sur-Rolle, Suiza. Se descartarían que las anotaciones fueran del propio Ernst, y se barajaría la posibilidad de que hubiesen sido realizadas, bien por la pintora Alice Vollmer, mujer de Ernst, y discípula de Georg Munche y Paul Klee, o por un tal Andreas Vollmer, del que apenas quedaría rastro, y que habría sido, al parecer, durante años, ayudante (¿secretario?, ¿chofer?, ¿arquitecto?) del arquitecto.
\end{abstract}

Este descubrimiento supondría, no sólo una nueva perspectiva respecto a ese Arte de Proyectar en Arquitectura (con todas las contradicciones que ello implica), sino respecto a lo que hasta ahora hemos entendido (que entendían) por función, o por medida.

Palabras clave: Ficción, Neufert, Vollmer, marginalia, hallazgo.

\begin{abstract}
Imagine the recent finding of a copy of the first edition of the Art of Projecting in Architecture, full of amazing annotations on the margin, and not so on the sidelines, would throw a new interest, and completely unexpected, on what has been for a long time, the manual of standardization and the top of function.

The large vademecum would have been found in the last house of Ernst Neufert, in Bugneaux-sur-Rolle, Switzerland. It would be ruled out that the annotations are from Ernst himself, and the possibility that they have been made, either by the painter Alice Vollmer, Ernst's wife, and disciple of Georg Munche and Paul Klee, or by one Andreas Vollmer, from whom there would hardly be a trace, and who would have been, apparently, for years, assistant (secretary?, driver ?, architect?) of the architect.

This discovery would suppose, not only a new perspective with respect to that Art of Projecting in Architecture (with all the contradictions that this implies), but with regard to what until now we have understood (that they understood) by function, or by measure.
\end{abstract}

Key words: Fiction, Neufert, Vollmer, marginalia, discovery. 


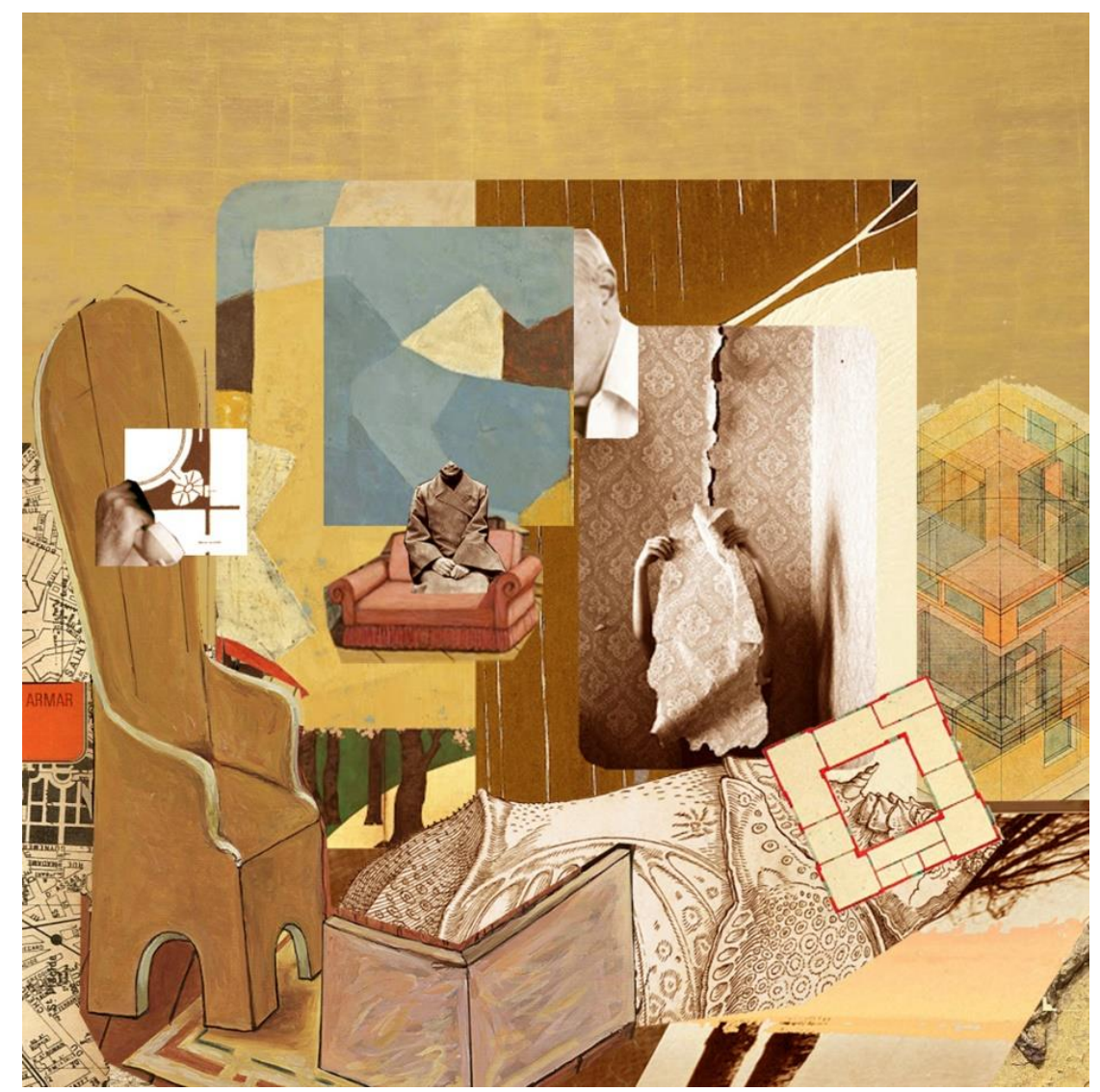

Fig.1 Collage a partir de las diversas conjeturas del artículo.

El reciente hallazgo de un ejemplar de la primera edición del Arte de Proyectar en Arquitectura $^{1}$, repleto de asombrosas anotaciones al margen, y no tan al margen, arroja un nuevo interés, y completamente inesperado, sobre el que ha sido durante mucho tiempo el manual de la normalización, y el estandarte de la funcionalidad por excelencia.

El gran vademécum en cuestión ha sido encontrado en la que fuera la última casa de Ernst Neufert en Bugneaux-sur-Rolle, Suiza, por la investigadora turinesa Tina Nemour, mientras realizaba el inventario de la biblioteca del arquitecto. El libro se encontraba en la segunda fila del estante superior, entre un manojo de cartas de los años 20 y 30 dirigidas al propio Ernst (que han sido estudiadas convenientemente), y una primera edición

\footnotetext{
${ }^{1}$ Bauentwurfslehre. Handbuch für den Baufachmann, Bauherren, Lehrenden und Lernenden; Aprendizaje de Construcción. Manual para Arquitectos, Constructores, Profesores y Estudiantes. El libro nació a partir de la documentación recogida para una serie de conferencias Bauhochschule de Weimar, consistente en mediciones, variables métricas y conocimientos adquiridos por el arquitecto a lo largo de su experiencia profesional. Se publicó por primera vez en Marzo de 1936.
} 
en alemán de Modelo para Armar de Julio Cortázar (que también). Al principio se pensó que las cartas podrían ser de F.LL. Wright, ya que sus iniciales figuraban en el remite de los sobres, y estos procedían de los EEUU. Ernst llegó a visitarle personalmente en Taliesin, en su estancia en los EEUU, a finales del año 1936. Pero los pliegos interiores proceden de Rusia; dos fueron escritos desde Moscú y uno desde Siberia, y pertenecen a Pável Florenski, matemático, filósofo, historiador del arte y sacerdote ruso.

De manera que al misterio del ejemplar del Neufert, se suma el de estas cartas deslocalizadas, y el de la novela de Cortázar. Sus localizaciones, a uno y otro lado del ejemplar, no parecen azarosas; son citados y transcritos en notas interiores al Neufert, y serán, por tanto, abordadas aquí posteriormente.

Además, entre las páginas del manual, se han encontrado: una lámina de la obra Mobili nella valle, de Giorgio de Chirico $^{2}$, y una cuartilla doblada por la mitad con un texto titulado Monstruo y prodigio. Ambos hallazgos serán analizados al tratar los capítulos entre los que se encontraban y en los que se hacía referencia directa e indirecta a su contenido.

Se ha descartado totalmente que las anotaciones sean del propio Ernst, y se sostiene la teoría de que hayan sido realizadas, bien por Alice Vollmer, pintora, mujer de Ernst (al que conoció en 1926), y discípula de Georg Muche y Paul Klee, o por un tal Andreas Vollmer, del que apenas queda rastro, y que fue, al parecer, durante muchos años, ayudante (¿secretario?, ¿chofer?, ¿arquitecto?) del arquitecto. El estudio de las dos caligrafías no ha hecho sino acentuar la duda sobre la autoría porque, si bien la letra asemeja a la de Alice (presa de alguna agitación), también podría ser la de Andreas (deformada sutilmente por el poco espacio disponible y la necesidad de empequeñecer la letra). Claro que cabe otra posibilidad: que Alice y Andreas colaboraran en el manuscrito, o que Alice y Andreas fueran en realidad la misma persona, y sean las variaciones encontradas, las variaciones de una misma letra a lo largo del tiempo y de las circunstancias.

En cualquier caso, se trataría de una persona lo suficientemente cercana para tener acceso al libro, y a la estantería, en aquella época (pues las anotaciones se han fechado efectivamente en torno a los últimos años 30 y principios de los 40), y lo suficientemente lejana (una lejanía típica de la proximidad), para tener (otra) perspectiva respecto a los temas tratados y a la figura del arquitecto. No podemos obviar la excelencia de esta distancia, y de las apreciaciones indirectas que provoca, ni la lucidez de las aportaciones de aquellos supuestos papeles secundarios, eclipsados por el papel protagonista. Estos eclipses también propician un espacio-tiempo adecuado para reflexiones e inspiraciones

\footnotetext{
${ }^{2}$ Pintor italiano nacido en Grecia y fundador de la denominada 'Escuela metafisica'. Como 'Meta' significa 'más allá', podríamos traducir metafísica como 'más allá de la fisica'. Pero muchos cuadros de Chirico, y en especial Muebles en el valle, paracen estar no más allá, sino más acá de la física. O en un entramado hecho de las dos posibilidades de acercamiento - alejamiento.
} 
muy provechosas. Y, no obstante, la relación entre artistas y colaboradores, o ayudantes, o chóferes, o secretarios, o esposos, casi nunca es, por mucho que se empeñen, como la de planetas y satélites. $\mathrm{O}$ al menos no en este orden, y no siempre.

Sobre la naturaleza de los comentarios, ya sean en forma de palabras o dibujos, podemos decir que tienen el tono, y también el ritmo (a veces acelerado, pero solemne), de los diarios de los primeros exploradores en tierras lejanas, o el de los primeros (y últimos) astronautas en habitar el espacio, pues sus confesiones son también marginales, quizá no en márgenes literales, pero sí circunstanciales, de la intemperie reinante. Son también apreciaciones cultivadas (de cultivo), que no es lo mismo, sino en muchos casos lo opuesto, que decir eruditas. Reflexiones propias de una mente inquieta y absorta, que bien podría haber encontrado unos interlocutores adecuados (adecuadamente inadecuados) en el arquitecto, pintor, grabador y escritor alemán Georg Muche (a cargo de la Exposición de 1923 de la Bauhaus, para la que diseñó la casa experimental "Haus am Horn" $^{3}$ ) y en el pintor alemán nacido en Suiza, Paul Klee, cuyo estilo, dicen, parece variar entre el surrealismo, el expresionismo y la abstracción, como por cierto, las notas al margen a las que nos referimos.

La marginalia ${ }^{4}$ de la que hablamos, que no pocas veces salta del margen, al interior de textos y dibujos, retocando posturas y medidas, y ampliando posibilidades, no sólo afecta a los distintos capítulos centrales, sino que reestructura los preliminares con, por ejemplo, un índice que transcurre paralelo al impreso, hecho de palabras destacadas y relacionadas mediante una serie de líneas y flechas.

Índice de un Tratado, supuestamente de Arquitectura, pero también en cierto modo, de Antropología, y de sus consecuencias. Algo a lo que tal vez podríamos llamar Antropografía, y que parece indagar los rastros del espíritu de una época que perseguía 'el futuro', como quien persigue un sueño. Un sueño de esos que uno recordaría al despertar y en el que parecía imprescindible saber medir lo soñado, lo vivido. Las anotaciones de los márgenes parecen preguntar: ¿Qué hay de los aspectos situados en territorios menos medibles, o medibles de otros modos? Nos hemos visto acotados. Y además se ha considerado el espacio necesario para limpiar la bañera. Pero, y esto ya lo insinuaba también Ernest, esto es, si acaso, un principio. Aquí hay una percepción del que llega (y acota), pero no del que se queda y habita. Tampoco del que deshabita, del que se va.

\footnotetext{
3 'La palabra 'Haus' significa casa, 'am' es una contracción de 'an dem': en, en un lugar... 'Horn' puede ser trompeta (de caza), cuerno... Todo depende del contexto, pero una muy posible traducción al castellano sería: 'Casa en el cuerno'

${ }^{4}$ Marginalia es una voz latina que sirve para designar las notas, glosas o comentarios hechos al margen de un libro. El término no sólo se aplica a textos, sino también a dibujos, como en el caso de los manuscritos ilustrados medievales. El término fue acuñado por Samuel Taylor Coleridge (1772-1834), poeta y filósofo británico, que realizaba extensas notas al margen en todos los libros que leía. La práctica, en sí, es muy anterior a Coleridge. Edgar Allan Poe tituló algunas de sus reflexiones Marginalia.
} 
Tina, que extraoficialmente se refería a este ejemplar anotado como: 'El (ejemplar) Vollmer', ya se refiere oficialmente así también a él. Haremos lo propio y procederemos a analizar el Vollmer en su estado, digamos, natural: entretejido al Neufert (y a su periferia), dialécticamente, sin síntesis. ${ }^{5}$

Ya en las primeras páginas del Neufert, las de los CAPÍTULOS PRELIMINARES, a través de esas líneas de subrayado o de envolvente, y de símbolos de exclamación e interrogación se sientan las bases de las reflexiones posteriores. Se puede intuir hacia donde se dirige, y también de donde viene, la mirada de la autora o autor o autores de las mismas. Y donde decimos autora, debemos decir también lectora. Porque en este caso la escritura es la de una persona que va leyendo y conforme lee, escribe. Un lectorautor; una apropiada apropiación.

Para empezar, tras la HOJA DE CORTESÍA, encontramos una primera y sintomática corrección al título de esa primera edición. Donde dice 'Arte de proyectar: La medida de las cosas', se ha escrito, entre la y medida, el equivalente a nuestro (suficientemente ambiguo) prefijo des. Y es sólo cuando llegamos a ese punto de la hoja que nos damos cuenta de que en la hoja anterior, en el envés de la hoja de cortesía, hay una anotación en el borde inferior. Dice: Reflexionar sobre la cortesía y también; situar otra hoja de cortesía, y un capítulo, entre el capítulo de puertas y el de ventanas.

En el PRÓLOGO a esta primera edición, donde Ernst Neufert decía: 'Si el lector echara en falta algún dato importante para la proyección, ruego que me lo comunique para tenerlo en cuenta en futuras reediciones'. Está muy subrayada la palabra 'dato'. De la que parte una línea que acaba en flecha que apunta a la siguiente anotación: Información concreta sobre hechos. Y debajo: pero también, necesariamente, sobre los no concretos.

En los PROLEGÓMENOS, allí donde Ernst cita las palabras de su colaborador, Fritz Schumacher reflexionando sobre la proyección de arquitecto ${ }^{6}$, encontramos dos líneas muy distintas englobando ese mismo párrafo: una es gruesa, a lápiz (a la manera en la que Ernst englobaba) y otra más fina, hecha con la misma estilográfica y estilo de las anotaciones Vollmer. Si así fuera, es el único momento del ejemplar, en el que coinciden una anotación de Neufert y una de Vollmer. Como cuando a dos

\footnotetext{
${ }^{5}$ La dialéctica sin síntesis (donde conviven tésis y antítesis), es conocida como 'La dialéctica negativa' (aun siendo muy positiva). Fue formulada por el filósofo Theodor W. Adorno.

6 'El joven arquitecto se pierde a menudo en consideraciones histórico-arquitectónicas, en investigaciones retrospectivas y, dejándose seducir por el título de doctorado, emprende caminos secundarios de erudición, lo que se realiza a costa de las fuerzas necesarias para las múltiples exigencias de la creación arquitectónica.'
} 
personas muy distintas les gusta una misma cosa, sólo que por razones diversas, o con lecturas e interpretaciones muy distintas. O como cuando sueños muy distintos, por distintas razones, convergen en la misma forma.

En las INSTRUCCIONES DE CONSULTA, cuando dice 'El orden que siguen los diferentes temas abordados en el manual se ajustan al curso natural del proceso de construcción.' Se añade: ¿Pero qué curso natural del proceso de proyectar?

Cuando pregunta ‘¿Cómo se utiliza el libro?’ se añade: ¿Cómo se utiliza un libro?

Las frases: 'Se lee cuidadosamente el cuestionario, se responde a las preguntas, se calcula el volumen construido, se modifica según normas y condiciones económicas y luego se proyecta el edificio' y 'Sobre esta base, el proyectista podrá desarrollar su trabajo de forma segura y rápida, adecuándose a los requisitos particulares del encargo y a las condiciones del paisaje, conforme al espíritu de su tiempo.', están tachadas.

Debajo está escrito: Yo sólo veo hombres confundidos.

En el CUESTIONARIO (donde aparecen tachadas las dos últimas letras) sólo encontramos unas líneas destacadas en el primer apartado, relativo a la Información sobre el cliente. Son las cuestiones número 7: ¿¿Quién nos pone dificultades? ¿Por qué? ¿Qué consecuencias puede tener?'

En el ÍNDICE ANALÍTICO se han ido señalando y/o agrupando diferentes palabras de los distintos capítulos y/o subcapítulos. Las que nos parecen más significativas son:

En 'Normas fundamentales (Unidades, formatos, suministros e instalaciones)' sólo aparecen dos subcapítulos subrayados: el tercero: 'Dibujos'. Y el último: 'Dibujar.'

En 'Dimensiones básicas. Proporciones.' Otra vez aparece el prefijo des antes de proporciones. Sólo aparece subrayado el subcapítulo sexto: 'Clima interior'. El resto de subcapítulos, aparecen agrupados con una línea y varios interrogantes: ' $E l$ hombre como unidad de medida', 'El hombre escala de todas las cosas', 'El hombre. Dimensiones y espacio necesario', 'Hombre y vehículos. Espacio necesario en vagones', 'Hombre y hábitat', 'El ojo. Percepción', 'El hombre y los colores. Proporciones .Fundamentos', 'Proporciones. Aplicación: el Modulor'.

Debajo, en un paréntesis, está escrito: 6 Hombres, 1 Ojo, 3 Proporciones.

En 'Proyectar' están subrayadas las palabras: 'expresión', 'época', 'proceso', 'preliminares'. Y en 'Cuestionario' se vuelven a tachar las dos últimas letras.

En 'Ejecución de obras': 'Medidas fundamentales'. Entre medidas y fundamentales hay una coma. Antes de medidas, entre paréntesis, otra vez: des. En 'Distancias entre ejes', tachado: ejes. 
En 'Elementos de construcción': 'Hogares', 'Armaduras', 'Desvanes', 'Directrices de la asociación de jardinería', 'Arquitectura textil' (aquí se ha añadido: trajes).

En 'Física de la construcción' (entre paréntesis, debajo, aparece: del equipaje): 'Detalles', 'Sonido propagado por sólidos'.

En 'Alumbrado. Iluminación. Vidrio': 'Materiales transparentes y translúcidos'.

En 'Puertas y ventanas': 'Lucernarios. Cúpulas transparentes. Desvanes. Puertas', 'Grandes puertas y Mecanismos de cierre' (añadido: y apertura). Sale una flecha que lo une al siguiente capítulo:

'Escaleras. Ascensores': 'Escaleras de caracol', 'Mecánicas', 'Para personas', 'Panorámico'.

En 'Viales': 'Cruces'.

En 'Jardines': 'Caminos', 'Contención'.

En 'Espacios auxiliares en viviendas': 'Cortavientos', 'Pasillos', 'Trasteros', 'Elementos adosados y empotrados. Vajilla y Mobiliario'.

En 'Espacios de las viviendas': 'Posición de las camas'.

En 'Piscinas. Lavanderías. Balcones. Caminos'. Todas las palabras que conforman el título del capítulo están unidas por una línea al final de la cual se lee: poema.

En 'Tipología de viviendas' está tachado 'logía' y se ha añadido: grafía. Se subrayan las palabras: 'Vacaciones', 'Camarotes', 'barco', 'Casas en jardines' (añadido: Jardines en casas), 'Orientación en ladera', 'Plantas', 'Refugios'.

En 'Galerías y edificios comerciales': 'Pasajes acristalados' Se añade: de avión, literarios... Y debajo de pasajes: paisajes. Entre paréntesis: WB, Des Passagen-Werk $1927^{7}$.

En los capítulos siguientes, apenas aparecen indicaciones, a excepción del subrayado de las palabras 'pasajeros', en 'Ferrocarriles', y de 'giros' en el capítulo 'Aparcamientos. Garajes. Estaciones de servicio', y del dibujo de dos líneas; una une cuatro capítulos consecutivos con una exclamación: 'Aeropuertos', 'Restaurantes', 'Hoteles. Moteles', 'Zoológicos' y 'Teatro. Cines'. (En 'Restaurantes' se ha subrayado el subcapítulo 'Restaurantes en trenes'.) La otra línea une los capítulos de 'Iglesias' y 'Museos' con el siguiente; 'Cementerios'. En 'Iglesias. Museos', aparece subrayada la palabra 'Órganos'.

\footnotetext{
${ }^{7}$ Walter Benjamin trabajó desde 1927, hasta su muerte en 1940, en el 'Libro de los Pasajes', una obra sobre París y una filosofía de la historia del siglo XIX. Consideraba los pasajes comerciales de París, síntomas ejemplares de una época (paisaje intelectual del sXX), capaces de recoger, como título, las notas y materiales de su 'mitología moderna'.
} 
En 'Medidas. Pesos. Normas': 'Sobrecargas de uso'. Debajo: Sobrecargas de desuso.

En 'Bibliografía', subrayado: 'grafía'.

En 'Índice alfabético' hay un asterisco que remite al ÍNDICE ALFABÉTICO, tras la bibliografía, donde se seleccionan las siguientes agrupaciones de palabras:

'Asoleo, tiempo de-Aspiradores domésticos-Atletismo -Audición, umbral de. I Autopistas, enlaces-Autoservicios-Aves acuáticas-Aviones, movimientos-AxonometríaAzoteas/ Badminton-Baile, deportivo-Bajantes. / Barandillas-Barcos-Barcos con quilla-Barra de bar. / Calor-Calle-Cama-Cámara-Camerinos-Caminos-CamionesCampanario- canal. I Cabaña votiva-Cabeza humana, longitud de la.-Cabina de proyección-Cabina telefónica.'

En EXPLICACIÓN DE LOS SÍMBOLOS Y ABREVIATURAS también se señalan relaciones entre palabras consecutivas:

En 'Abreviaturas y simbolos en las plantas':

'Alacena. Antesala. Armario / Baño. Biblioteca. Balcón. / Cortaviento. / Guardamaletas. / Jardín invierno. / Sala de té. / Entrada secund. / Arte de proyectar. Arte de construir. / Hombres, Mujeres, marea alta, marea baja / Casi, aproximadamente, según, relativo, compárese, en algunos casos.'

Por último, aparecen subrayadas las siguientes frases de NORMAS FUNDAMENTALES:

En 'Disposición de los dibujos': 'Las cotas de los elementos no dibujados a escala se han de subrayar'. Esta última palabra, subrayada.

Y en 'Simbología empleada en los planos de arquitectura':

'Piano / Envolvedor / En Guardarropía: Armario- Escritorio- Florero / Las puertas giratorias. / En las horas punta las hojas de la puerta se han de plegar. / Rojo vapor / Salida de humedad, moho, manchas, etc...y escrito entre paréntesis: territoriales / Pero aún no construidos / Construcción a demoler / Representación con un solo color / Las anchuras también se han de respetar en los dibujos de tinta / Elementos situados por detrás del observador (frase subrayada)/ Conjunto de una vivienda conectada a una bajante (baño, aseo y cocina) / De manera que desaparezca el peligro / Un mapa de precipitaciones / Entre paréntesis / Jardines pequeños / Tan pronto como la conducción básica abandona el edificio, se ha de proteger frente a posibles heladas.'

En los CAPÍTULOS CENTRALES del libro, el modo de anotar varía respecto al de los capítulos de los extremos, transformándose en una profusa colección de conjeturas es- 
critas y dibujadas, no sólo en los márgenes, sino también en no pocos centros, propiciando, como indica Neumer, una suerte de 'márgenes de interior'.

El estudio de estas anotaciones y reflexiones, encontradas a lo largo (y sobretodo ancho), de los diferentes capítulos centrales, ha hecho posible agruparlas en torno a un concepto del que todas parecen partir (en el sentido de irse, pero también de romperse): la función. Así, hemos podido extraer una serie de funciones, llamémoslas 'Vollmer' que pondrían en crisis, por incompleto e insuficientemente cercano a la vida, el modo de proyectar según Neufert, completándolo y tensionándolo. Un contra-Neufert que reside en el mismo Neufert, tal y como se intuía en las palabras y frases seleccionadas en los capítulos anteriores.

En este sentido, convendría abordar antes de nada (pues antes de nada es citado en el Vollmer), la figura, pero también el fondo, del autor de las tres cartas rusas, en sobres americanos, que se encontraban en la estantería, al lado del Neufert. Su nombre aparece anotado en dos ocasiones en el libro; debajo de la palabra 'espacio' y encima de 'perspectiva': Pável Florenski.

Las dos primeras cartas fueron enviadas en los años 1922 y 1925 desde Moscú. En efecto, desde 1921, Pável fue docente en la Escuela de Arte y Técnica de Moscú (Vjutemás), ocupando la cátedra de 'Análisis de la Espacialidad en la Obra de Arte' y ocupándose de la asignatura: 'Teoría del espacio'. Allí es donde empezó a trabajar en un amplio ensayo sobre el análisis del espacio, al que se refiere extensamente en sus cartas. También hace referencia a su Tesis en matemáticas, titulada: 'Sobre las peculiaridades de las curvas planas como lugar de discontinuidades'. Pero sobre todo, aborda la cuestión de la perspectiva. En este sentido, estaba decidido a romper las ataduras de la perspectiva lineal (aquella con un único punto de convergencia en la lejanía), que desde el Renacimiento, se había instituido como único sistema geométrico para objetivar la experiencia de la realidad. Entendía que era posible otra perspectiva capaz de entrar en la realidad tangible de las cosas, en la estructura invisible de su realidad metafísica. Como la perspectiva invertida de los iconos rusos. O la vuelta al estado salvaje de por ejemplo, la pintura bizantina.

La última carta es del año 1935, desde Siberia. Había sido arrestado por segunda vez (dicen que la Revolución soviética, iluminó y luego traicionó sus sueños) y condenado a diez años de trabajos forzados, primero en el lager de Skovorodino, en Siberia occidental, y luego en el de Solovki, en el mar Blanco. En ella, además de hablar con entusiasmo de la publicación que había causado su condena, la monografía titulada 'Los números imaginarios en la geometría', sobre la teoría de la Relatividad de Albert Einstein, relata las nuevas investigaciones en las que estaba inmerso. En condiciones de vida extrema, sus últimos trabajos versaron sobre los hielos 
perpetuos, alcanzando descubrimientos importantes, aun hoy, en el terreno de los anticongelantes.

El 25 de Noviembre de 1937 fue condenado a muerte por un tribunal de Leningrado. Después de cinco días de viaje en tren, fue conducido a un bosque en los alrededores de la ciudad donde el día 8 de diciembre recibió un tiro en la nuca. Un año y nueve meses después de la publicación de la primera edición del Neufert.

Precisamente a un bosque recurría A. Vollmer para acompañar, mostrando, la primera de las funciones que no fueron tenidas en cuenta por E. Neufert. Funciones que destilamos a continuación y que conforman un listado-ensayo de funciones a contrapelo:

-La función desmedida. O la medida no corriente. A.Vollmer escribió entre comillas: 'El bosque de álamos debía proteger el jardín de los vientos'.

-La función residual o marginal: preferencia por los segundos planos o detalles insignificantes de una película, a la trama principal. La de las cosas (y espacios) que acaban usándose para cosas distintas, o incluso contrarias:

-La función contraria.

-La función inesperada, la impensable: excéntrica. ¿Deberían tener más peso las actividades que realizamos día tras día, o las extraordinarias? Lo impensado desvelado por los acontecimientos extraordinarios, o por los cotidianos, mirados de otra forma. La función pública de lo eminentemente privado. La función privada de lo público. La utilidad de todo aquello que pensábamos que no lo era. O que lo era en un sentido pero no en otro. Espacios que parecen girar sobre sí mismos antes de posarse. Lo casi confortable. Reconsiderar los vientos dominantes. Reconsiderar la función inesperada adquirida con el tiempo.

-La función variable. La función está en manos del que habita (aunque sea de paso). La posibilidad incluso de que un lugar se convierta en un objeto, un objeto en un lugar. Tina Nemour refuerza esta idea con una alusión al secretario de Picasso, Jaime Sabartes, cuando recordaba cómo el pintor, cuando inició su obra escrita, ocupó el comedor dónde ya no cabía nada más; 'En el lugar donde suele apoyar la mano siempre habrá un espacio suficiente, por reducido que sea, para apoyar la libreta de bolsillo y escribir'. 'Lo que quiere, en realidad, es apoderarse del comedor para convertirlo en escritorio. 'Habría entonces una tilde diacrítica de los lugares, transformando su función. Ambigüedad latente de todo espacio que se precie y/o se desprecie. ¿Quién pone esa tilde? ¿La persona que habita, la persona que pasa, un clima en concreto, algo en el lugar, un objeto que?

-La función infra-escalar (en el entre de las escalas): Importancia territorial de los detalles: un árbol en el camino. Función menor de lo territorial: un camino en el árbol. Las funciones propias de las palabras que atraviesan seres muy distintos: lomos 
(de libros, de montañas, de animales), tejidos (huesos, telas, geografías...), accidentes, espacios. Las asombrosas relaciones y correspondencias entre lo mirado al microscopio y lo mirado al telescopio.

-La función extraña. Y la función de lo extraño, lo desconocido. La función representativa insólita, o contradictoria. La de las paradojas espaciales. La función de no tener función. Las arquitecturas espontáneas como gestos raros, sin explicación.

-La función familiar. ¿Pero para quién? ¿Y hasta donde debe llegar, por ejemplo, la utilidad de una casa? ¿Dónde empieza? La función de lo útil, de la vida útil. Cuando algo funciona ¿respecto a quién? ¿respecto a qué? La vida útil de un espacio, que como un abrigo, pueda desvariar en otro, dándole la vuelta, o convertirse en trapo. Escrito: Otorgar a lo familiar la dignidad de lo desconocido. Y debajo: Otorgar a lo desconocido la dignidad de lo familiar.

-Lo útil para todo. Algo que sirve para muchas cosas, o algo compuesto de muchas cosas, cada una útil para algo. Y cuando todo acaba siendo usado para algo, pero fragmentado, en distinto lugar cada cosa, o lugar. ¿Hay lugares equivalentes a las partes de un cerdo, tras su muerte, donde nada tiene desperdicio, alejado del todo?

-Lo útil para nada en concreto. Lo no exactamente útil para algo en concreto. La función no específica, y la utilidad y necesidad de los espacios que no son nada en concreto. Grados de estos lugares. Tanto en los campos, como en las ciudades, como en una casa, como en un cajón.

-Lo útil de lo inútil. Relectura contemporánea de aquellos espacios que fueron juzgados erróneamente como no funcionales, como la sucesión de habitaciones iguales pero con distinta orientación donde residir según las estaciones. Lo útil (y heroico) de lo que ya no exactamente útil: ¿No es acaso el descampado lo único que queda de campo, su resistencia? ¿No es acaso el desnudo lo único que queda 'nudo' respecto a los alrededores? La búsqueda de una utilidad distinta, y la recuperación de un cierto estado salvaje en la decadencia. Uso del desuso:

-De lo que está fuera del tiempo: Anacronías. Una reflexión sobre las cosas que ocurren en el espacio, y aquellas otras que suceden en el tiempo. Y anomalías.

-De lo que está fuera de lugar (Hendiduras en el aire). O de las cosas ya sin lugar, pero todavía con función. No sólo los objetos encontrados a reacción poética ${ }^{8}$, también los lugares encontrados a reacción poética. Pensemos también en la posibi-

\footnotetext{
8 'Les objets à reaction poetique', son aquellos objetos encontrados de los que se rodeaba Le Corbusier en su vida diaria, y que inspiraban sus reflexiones y trabajos.

'Objets trouvés': El aprovechamiento artístico de los objetos de desecho, que el movimiento Dadá y el surrealismo practicaban, aparecieron diez años antes de que André Bretón publicara el Manifiesto surrealista, con los objetos encontrados de Marcel Duchamp.
} 
lidad de perder objetos con esa misma reacción, o lugares: ¿Cómo sería perder un lugar a reacción poética? ¿Cómo sería des coleccionarlos?

-De los Pasos perdidos. Nadie duda de la utilidad de un salón de pasos perdidos. ¿Cómo serían las ciudades si este lugar hubiera sido considerado imprescindible también para las viviendas sociales? ¿Existió o existe en alguna civilización el $s a$ lón de los pasos encontrados?

-De los objetos. Hay, referidas a esta función, una serie de reflexiones que saltan de una página a otra, en torno a la lámina que se encuentra justo entre ellas: Muebles en el valle (1927). Esta lámina está dedicada a A.Vollmer por Giorgio de Chirico, con cuya familia tal vez estableció contacto, cuando el artista se mudó a Alemania en 1906, para ingresar en la Academia de Bellas Artes de Múnich. Encontramos dos anotaciones, que se encuentran, en el borde lateral izquierdo: ‘Cuál es la función real de los objetos? ...No sé si el mundo de las cosas se caracteriza, por una infinita lejanía a la vida de las personas, o por una infinita cercanía' (se añade: $o$ por las dos), y 'Temblor en nuestras categorías de interior y exterior: Objetos de la calle, puestos en casa. Objetos de casa, en el exterior. También: Muebles diseñados como casas. Casas como muebles.'

-De las reuniones de objetos (y usos) muy diversos, y dispersos. Propios de las relaciones que cuando se piensan resultan chocantes pero que son corrientes, asumidas; Tiendas de: Bicicletas - llaves - zapatos. O: mapas - rocas - conchas - minerales astronomía. Lugares para la relación de una transversalidad inusitada, en los que además, podemos encontrar un rincón con bolas del mundo de distintos tamaños que conformando un sistema no solar. O los objetos ultra-marinos, o reuniones dispares de libros u objetos muy distintos propiciadas por chamarileros.

-De lo roto. Está escrito: Alguien dijo que en Nápoles sólo funciona lo que está roto. La recuperación de su valor, otro valor, incluso para las obras de arte. Entre paréntesis: arte-sano distinto de ¿arte-loco = ARTE? ¿Cómo sería un espacio roto? La crisis de la función podría ser su despertar.

-De lo equívoco. Como cuando una especie parece querer ser otra (vegetales en disposiciones animales). Como cuando un espacio parece querer ser / o estar a punto de ser/ de otro. Como las personas que parecen ir juntas en un tren (largo trayecto) o en el metro (de una parada a otra, o un instante de cruce) pero no. Y cuando el equívoco es nuestro, no del espacio.

-De lo incierto. Allí donde habitan, sin síntesis, las contradicciones. Las posibilidades posibles. Como el momento en el que no sabríamos decir si un tren está llegando o yéndose. Hay al respecto, entre exclamaciones, la transcripción de una crítica 
de la época a Modelo para armar': 'No se sabe por qué ocurren las acciones, no está claro cómo se relaciona cada personaje con otros y no se respeta la línea de tiempo ni la del espacio...el texto permanece ajeno a las relaciones y sugiere un orden diferente. '. Comentarios que, paradójicamente, valdrían también para el Neufert. Y para el Vollmer.

-De lo que sirve para algo/alguien que no está y que probablemente nunca estará. ${ }^{10}$ Espacios reservados para lo que vendrá. Espacios vacíos, que esperan. Espacios ocupados, si acaso, por el deseo.

-De las distancias. Escribe: 'Salvemos las distancias'.

-De lo que se acaba, de los finales. Arquitecturas y despedidas. Las funciones perdidas. Escribe: 'Se acabó la función'.

Muchas de las reflexiones Vollmer están acompañadas, o protagonizadas, por DIBUJOS. Unas veces son bosquejos independientes y otras, modifican esquemas existentes. En ellos se hace evidente la predilección por los espacios de espera o transición, atravesados por la intención de quedarse en ellos. O la capacidad de ver en los lugares donde quedarse, espacios para el movimiento.

Por ejemplo, hay un dibujo en el que se amplía el pasillo hasta un árbol en la esquina de la hoja. Y hay otro en el que amplía el árbol hasta el pasillo. También hay un dibujo de un ascensor ¿transparente? que transcurre paralelo a un árbol (y a un bosque), y que recuerda muchísimo al ascensor de servicio del Sanatorio Paimio de Alvar Aalto, en Finlandia, 1929-1933. En realidad, muchos de los dibujos recuerdan, directa o indirectamente, a elementos o espacios secundarios de arquitecturas estelares (o estelarmente secundarias) de la época, e incluso muy posteriores; hay un árbol muy inclinado que parece alumbrar y evocar al propuesto por Francisco Javier Sáenz de Oiza para la plaza San Francisco en Mallorca, en 1991. También los hay que recuerdan a arquitecturas muy anteriores; escaleras indómitas que parecen sacrificarse rellenando huecos en torno a un centro colosal, como las de Andrea Palladio en Villa Rotonda, 1566.

Dice Ernestina Nemour: 'Al reunir todos los dibujos en una mesa hemos tenido la sensación de estar ante las piezas de un puzzle muy importante. Un puzzle que po-

\footnotetext{
${ }^{9}$ Recordemos el papel decisivo que en la novela tenía el espejo del restaurante Polidor. Recordemos también unos versos de Elisabeth Bisohp al respecto, en Norte \& Sur (1946): Pero duda / sobre qué lado está dentro o fuera del espejo / Hay poco margen de error, / pero tampoco hay ninguna prueba. I Y si la mitad de su cabeza está reflejada, / la inteligencia, piensa, puede estar afectada.

10 ¿Se inspiró A.Vollmer en el fragmento de Modelo para armar que transcribimos a continuación? (También podría haberse inspirado en otras circunstancias, dado que no hace referencia alguna al mismo) 'Hélène, si les dijera que todo lo que están esperando (porque están ahí, esperando que alguien empiece a poner orden), si les dijera que todo se resume en ese lugar sobre la chimenea de mi casa de París, entre una pequeña escultura de Marrast y un cenicero, donde hay el espacio preciso para posar tu carta, esa que no me escribiste nunca.'
} 
dría representar el detalle constructivo de un pomo, o de la mano que, o de la habitación dónde, o de la ciudad en la que, o de los caminos para, las montañas de...'.

O todo a la vez. Porque el conjunto de anotaciones, ya sea en forma de palabras o de dibujos, tienen algo de prodigio, pero también de monstruoso. Se remiten las unas a las otras en un verdadero enjambre de asteriscos y asteriscos, entendiéndose para luego desentenderse, y al revés. Como si haciendo que ata cabos, los desatase, y viceversa. Como una constelación enmarañada pero a la vez, muy ordenada (por otro orden) que parece deleitarse en la pregunta: ¿Quién remite a quién? Hay pies de páginas, manos de páginas, ojos de páginas...Una monstruosidad.

Precisamente, el texto encontrado en una cuartilla doblada al final del libro, se refiere a un proyecto de monstruo incierto, muy precisamente impreciso, que se adaptaría al paisaje por contraste y por mímesis. Estaría compuesto (y descompuesto) por 'un hilo que acaba (o empieza) en espiral y que no se sabe si forma parte de él o es una coincidencia repetida', y un cuerpo hecho de 'cumbres nevadas y dunas del desierto (dependiendo del punto de vista del espectador), ojos de buey, pelos varios, lengua-charco, ojo-dedo-verrugas.' Sería a la vez, o dependiendo del momento: 'mamífero-manada, reptil, roca, cadena montañosa, pisa-papeles'. 'Cada lado interrogaría al lado que creías conocer. De muchas naturalezas: todas al tiempo y cada una a la vez'. Debajo, aparece un extracto del Tratado de Monstruos y Prodigios de Ambroise Paré (1575), 'del mayor monstruo-pez que se encuentra en el mar'. Se usa su carne, su lengua, tocino, láminas que salen de su boca... 'En cuanto a los huesos, los de la región fabrican con ellos cercados para sus jardines, con las vértebras, peldaños y asientos para sentarse en sus casas. Mandé traer una, que conservo en mi casa.'

Las últimas anotaciones de A. Vollmer se encuentran en los bordes superior e inferior de la cara interna de la tapa posterior del Neufert. Arriba, muy en el borde: 'Porque \&Y quién se atrevería a afirmar que sólo la verdad es real?' 11 y abajo, también muy cerca del canto: 'Nos separa una época entera y, ahora, una comarca de nieve.' 12

Cuando preguntan a Tina Nemour por la magnitud del hallazgo, declara, visiblemente afectada, que este descubrimiento no sólo aporta una nueva lectura en torno a lo que hasta ahora hemos entendido (que entendían) por función, o por medida; 'Es como si hubiéramos encontrado, ahora sí, la versión definitiva del 'Arte de Proyectar en Arquitectura', con todas las contradicciones que ello implica. Me pregunto en qué hubiera cambiado el mundo, y las aspiraciones de los arquitectos, si se hubiera publicado el Neufert de esta manera.'

\footnotetext{
${ }^{11}$ Frase encontrada en Diario de un hombre superfluo, I.S.Turguénev.

12 Frase de Mallarmé encontrada en Rimbaud, el hijo, de Pierre Michon.
} 
Preguntan también: '¿El Vollmer supone una discontinuidad o una continuidad?' La Nemour responde: 'Puede que ambas cosas... como aquellas incisiones apenas visibles superficialmente, pero muy profundas.' Luego añade: 'Sea como sea, ahora tenemos dos puntos de convergencia en la lejanía.'

Dos o más. Porque el Vollmer, que está en el Neufert, también está entre el Neufert (cuartilla y lámina), y un poco más allá del Neufert: en sus orillas. Allí donde las cartas y la novela, como si fueran también, en sí, notas al margen, flanquean el ejemplar. De manera que esta marginalia Vollmer, va de unos márgenes a otros, interiores, exteriores, de enveses, de haces, reinventándolos. ¿No es acaso el Vollmer, entre otras cosas, un alegato en favor de estos lugares, la evidencia de lo que (en) los márgenes son capaces?

El Vollmer también revela al Neufert como un enorme poema, equiparable a otros ${ }^{13}$ heroicos intentos de explicar el mundo, ya sea en forma de sonetos o algoritmos. Sus esfuerzos en el ámbito de la normalización, bien recuerdan a aquellos que pensaban llegar a las Indias, y alcanzaban América. Y frente a esos esfuerzos de afán conquistador, en busca de una apropiación del territorio, del conocimiento y de la razón, en nombre de la civilización, la manera de proceder del Vollmer, parece evocar la forma de estar en el mundo de los indígenas. Una manera de ser y estar, y de conocer, salvaje (en ciertos aspectos mucho más civilizada que lo presuntamente civilizado); su confianza en la sabiduría / intuición del cuerpo, el deseo, no de conquistar un territorio, sino de formar parte de él, junto a un tratamiento primordial y mágico, de lo desconocido, lo incierto, lo inexplicable. Entonces, este ejemplar Neufert-Vollmer bien podría ser considerado también como un ensayo (en su acepción de prueba, y de puesta en práctica) de re-unión (pero sin tratar de ocultar, sin olvidar, la fisura por la que se rompieron, y ahora se unen) de estas dos maneras de aproximación al mundo. Como si pudieran volver a unirse de nuevo, asimismo, todos aquellos saberes o conceptos que se separaron, con la intención de acotar más, delimitar mejor; ciencia y arte, racional e irracional, mente y cuerpo... Unirlos como en aquellas arquitecturas y territorios insinuados por las anotaciones Vollmer.

El tiempo, con suerte, convierte todo intento científico en poético, liberado del valor / función para la que fue creado, incluido su rigor. Como todos los intentos de compilación y de deseo. Allí donde reside el rigor esencial, atemporal; el poético. El Vollmer, elude al Neufert como método de erudición acumulativa de certidumbres, y le da la oportunidad de ser algo distinto, y aporta incertidumbres (certeras), y matices, y escribe: todo está en los matices, y más adelante: también hay matices territoriales, y después: matices luminosos y entre paréntesis, al lado: detalles luminosos - imagismo ${ }^{14}$, en cuya

\footnotetext{
${ }^{13}$ Por ejemplo, el poema filosófico De rerum natura, escrito hacia el año 50 a.C. por Tito Lucrecio Caro, o el ya mencionado Libro de los Pasajes de Walter Benjamín, o el Libro del desasosiego de Fernando Pessoa y sus heterónimos.

${ }^{14}$ El imagismo fue una corriente estética literaria de principios del siglo XX, que aislaba los objetos basándose en lo que Ezra Pound llamó 'detalles luminosos', yuxtaponiéndolos después para expresar una abstracción (método ideográmico). Los detalles luminosos serían, por
} 
yuxtaposición latía un modo de pensar, inseparable de un modo de hacer, y un prodigioso rescate de la poesía antigua; de su concisión, densidad y expresión clara. Una manera de mirar y entender la antigüedad, como nunca antes había sido mirada, entendida. Pues puede que el pasado sea aún más impredecible que el futuro.

Precisamente una de las citas más celebradas de Ernst hablaba, aunque (aparentemente) en otros términos, del futuro. Ernst Neufert decía: 'Somos hijos de nuestro tiempo y tenemos la mirada puesta en el futuro'. Y es posible que fuera así, que miraran realmente al futuro. Al futuro en el que alguien encontraría esto. Encontraría esto y lo miraría, como nunca antes había sido mirado, con detenimiento, tratando de (des) entenderlo. Porque tenían un Neufert, pero necesitaban (necesitamos) un Vollmer.

\section{REFERENCIAS}

CLARO, Andrés. Imágenes de mundo. Chile: Ediciones Bastante, 2016.

CORTÁZAR, Julio. Modelo para armar. Obras completas I. RBA, Instituto Cervantes, 2005.

FRANCALANCI, Ernesto L. Estética de los objetos. Madrid: La balsa de la Medusa, 2010.

FLORENSKI, Pável. La perspectiva invertida. Madrid: Ediciones Siruela, 2005.

NEUFERT, Ernst. Arte de proyectar en Arquitectura. Barcelona: Gustavo Gili, 2013. PARÉ, Ambroise. Tratado de Monstruos y Prodigios. Madrid: Ediciones Siruela, La biblioteca sumergida, 1575 / 1987.

SABARTES, Jaime. Picasso, retratos y recuerdos. Almería: Editorial Confluencias, 2018.

SCHMUCLER, Héctor. 'Notas para una lectura de Cortázar'. Los libros (nº 2): 20-27, Agosto 1969.

ejemplo, hechos significativos que iluminan al resto, términos inesperados pero precisos, imágenes de alta carga poética.. 


\section{BIO}

Ana Fernando Magarzo es arquitecta e investigadora por la Universidad Politécnica de Madrid (ETSAM). Realizó el Máster en Proyectos Arquitectónicos Avanzados (MPAA) en 2009-2010, colaborando posteriormente en los talleres de Paisaje y Transferencias del pensamiento contemporáneo de 2010 a 2014. Está acabando una Tesis doctoral en Proyectos Arquitectónicos (ETSAM) titulada Lo Infraordinario, que reescribe el libro del mismo título, de Georges Perec. Ha publicado el libro despaisajes (Mairea) y los artículos: La crítica, instrucciones de uso (Criticall 1), Lo que* aprendió de los fragmentos (MAPEO 15) y Especies de des-espacios (Branca 2). Pertenece al estudio C.Andrés + LL.Masía, de urbanismo, paisaje y planeamiento territorial, desde el año 2003. Y a la Escuela SUR de Madrid (CBA), desde el 2018.

Ana Fernando Magarzo is an architect and researcher by Polytechnic University of Madrid (ETSAM). He completed the Master's Degree in Advanced Architectural Projects (MPAA) in 2009-2010, subsequently collaborating in the Landscape and Transfers of Contemporary Thought workshops from 2010 to 2014. He is finishing a Doctoral Thesis in Architectural Projects (ETSAM) titled 'Lo infraordinario', which rewrite the book of the same title, by Georges Perec. He has published the book 'despaisajes' (Mairea) and the articles: Critique, instructions for use (Criticall 1), What he * learned from the fragments (MAPEO 15) and 'Especies de des-espacios' (Branca 2). She belongs to the office C.Andrés + LL.Masía, of urbanism, landscape and territorial planning, since 2003. And also to the 'Escuela SUR' of Madrid, since 2018. 